\title{
DIGITAL DOCUMENTATION IN THE CONSERVATION OF CULTURAL HERITAGE: FINDING THE PRACTICAL IN BEST PRACTICE
}

\author{
L. S. Beck \\ Institute of Archaeology, University College London (1.stewart.11@ucl.ac.uk)
}

KEY WORDS: Conservation, Documentation, Digital Photography, Method, Research

\begin{abstract}
:
Documentation of treatment is one of the central tenets of conservation as a profession, and a necessary aspect of the preservation of cultural heritage. Photographic documentation has been an essential technique for recording the nature of heritage objects and illustrating conservation procedures. The routine use of digital photography in recent years has opened many avenues to conservators, but also poses unique threats to the long-term stability of the conservation record. Digital documentation is subject to decay just as physical or 'analogue' records are, with the stark difference that digital data corrupts absolutely, where physical records can remain legible through various stages of deterioration. It is therefore necessary to understand the options that conservators have with regards to preservation of their records for the future. The various guidelines presently available regarding digital documentation may be synthesized into a coherent 'best practice' specific to digital conservation documentation. This practice, however, must be reconsidered within the framework of what is necessary to ensure that photographic records are preserved, versus what is feasible. In order to determine if conservators are aware of the limitations of digital technology, thirty practicing conservators were asked to respond to a questionnaire regarding their own documentation practices. The responses identified a lack of best practice, and indicated that there are multiple factors which prevent conservators from developing effective methods for creating, storing, and accessing documentation. To address this, a modified form of best practice, the 'best practical' method, is developed as a series of guidelines with the intent of being feasible for practicing conservators. This method aims to reduce the time and economic costs required of best practice, while minimizing the risk to the conservation record. The 'best practical' guidelines are being designed to be applicable to a wide range of professional contexts, from large public institutional conservators to independent private contractors. The significance of selection of documentation for long-term survival is also emphasized. The value of these guidelines lies in the identification of small changes to current practice that have the potential to make large differences in the amount of information preserved for future conservators, scholars, and other interested parties.
\end{abstract}

\section{INTRODUCTION}

Photography has existed for more than 150 years, but only recently have advances in technology made high-quality cameras and devices readily available, affordable, and easy to use. Digital technology in particular allows users to take more pictures than ever before. Museums have been able to make use of these advances, and today many conservators use digital photography for the purposes of documenting their work.

However, the advent of digital photography also brings about new issues that conservators must be prepared to address. The lifespan of the hardware used to store digital media can be as low as five years; paper and printed photographs can last as long as 100 years with minimal intervention (Carlston 1998). Extra resources must be dedicated to addressing this issue and prolonging the lifespan of photographic documentation. Are conservators prepared to address these issues? Have they begun, or are future conservators already facing a span of time from which information will be lost?

Many conservators bemoan the lack of documentation from before the end of the $20^{\text {th }}$ century, before conservation was established as a profession (Pye 2001). Conservators must acknowledge that when they use digital photography, they face many issues that have the potential to dramatically decrease the lifespan of their documentation. Failing to prepare for the future of their photographs could potentially leave future conservators without records from our time.

\subsection{Motivation and aims}

Documentation is one of the fundamental responsibilities of the modern conservation professional, and is emphasized in institutional policies as well as professional ethical guidelines. When properly completed, it can serve to inform future conservators of previous work, allowing conservators to track the efficacy of treatments over time. It can also serve to allow comparison between a previous state and the current state of an object, illuminating the rate of deterioration. To other museum professionals, documentation can be used to demonstrate the work that conservators do. These are only a few of the many benefits that documentation provides to conservators and others within the museum and academic communities.

The lack of documentation records from the early years of conservation parallels the loss of digital data through obsolescence and corruption that has occurred over the past quarter century in many fields. Some go so far as to say that the human record from the late $20^{\text {th }}$ and early $21^{\text {st }}$ century may be completely unreadable in the future (Deegan and Tanner 2006). A valuable point about the longevity of digital media has been made on multiple occasions: digital media corrupts absolutely, a stark difference from analogue media which has various stages of deterioration over time, many of which are still legible (Gschwind et al 2005).

Three significant issues have been isolated with respect to the longevity of digital media: the storage medium itself, the hardware, and the interpretive software necessary. For each of these, there are dangers of corruption of data or obsolescence of the software or hardware. (Carlston 1998) Multiple strategies have been suggested as a response to the frailty of digital media, and are widely used in the technical community. Refreshing, or copying material from one medium to another, is an effective strategy because no data is lost during replication (Gschwind et al 2005). Another way to accomplish this is by 'exercising' data, as using and resaving also prevents data loss and ensures that it will remain usable (Lyman and Besser 
1998). Another commonly used strategy, migration, involves transferring data onto newer hardware, protecting it from technical obsolescence (Greenstein and Beagrie 1998).

The aim of this research was to understand how conservators use photography as a form of documentation today. How do the issues presented affect conservators, and are conservators addressing these issues in a way that will allow their records to be accessible well into the future?

\subsection{Methodology}

The questions of recording, storage, and access were probed with respect to theoretical best practice as well as the current practices of conservators. Current practices in documentation were analysed using a questionnaire, with selected follow-up interviews. The questionnaire consisted of eighteen short questions, and was targeted at practicing conservators. Any interested conservator was welcome to respond to the questionnaire. Responses from 30 conservators were recorded. Of these, 18 responses were from conservators in museums, 7 were from conservators in private practice, and 5 were from conservators who chose to submit anonymously.

\section{DEFINING BEST PRACTICE}

There are a variety of sources that document 'best practice' when it comes to documentation, particularly photography. The AIC did recently publish a guide to digital photography for conservators, which is the first of its kind aimed specifically at the field of conservation. There are a good number of guidelines and standards that were not developed for the heritage sector, but are still applicable, such as the Universal Photographic Digital Imaging Guidelines (UPDIG) and guidelines published by the Scientific Working Group on Imaging Technology (SWGIT). The goal of each of these sources comes down to the same ideal: what can be done to ensure the preservation of photographs, especially digital photographs, for as long as possible? The recommendations of all of these sources are synthesized below into one set of 'best practice' standards for photographic conservation documentation.

\subsection{Documenting Conservation}

The first thing to consider when creating documentation is the stages within the treatment process where photographs will be significant. The AIC Code of Ethics suggests that records must be created before and after treatment documenting condition, but should also detail "examination, sampling, scientific investigation, and treatment" (AIC 1994). While this refers to all forms of documentation, not just photography, it illuminates the decision-making process for conservators. Photographs should be taken whenever written documentation could not succinctly describe condition before, during, and after treatment.

Given that conservators are not professional photographers, there are few photography specific details that are required by best practice. However, it is imperative that images are taken with colour targets and size scales included. In addition to using a colour target, the digital camera itself should be colour characterised in order to create photographs with the most accurate colour reproduction. This can be accomplished with colour calibration software from companies such as X-rite (formerly GretagMacbeth).

\subsection{Storage of Documentation}

First and foremost, best practice in the storage of documentary photographs involves not only multiple digital copies but physical or 'analogue' copies. In order to discuss the specifics of each type of storage, they will be dealt with separately, but it is important to remember that both methods of storage must be used.

The first thing that must be considered when storing digital data is the file format. The current standard is a TIFF file, with EXIF metadata attached, for uncompressed photographs. EXIF is a form of metadata that records information about the camera used to take the photograph as well as other technical metadata. Images should be named in such a way that the content of the file is easily understood; naming should be standardised across the institution (Keene 1998). The image should be converted to a standardised colour profile. The AIC guide suggests a variety of colour profiles, including but not limited to Adobe RGB, which has been adopted as a standard by many museums. Another important consideration is the resolution of the image. A minimum resolution of 300 dpi (dots per inch) is required, with $600 \mathrm{dpi}$ as the target resolution.

The next consideration is how many digital copies to store. It is recommended that a high resolution master file is maintained, unedited and uncompressed in TIFF format, while a lower resolution, compressed JPEG is also maintained as an 'access copy' of the image. The master file should never be manipulated; only the 'access' JPEG or another copy of the original should be changed in any way (Gschwind et al 2005).

Maintenance undertaken on digital storage is just as important as the methods of storage, as it ensures against catastrophic failures and keeps archives in working order. The AIC guide recommends maintaining multiple backup copies of data in separate locations, and randomly surveying to check for corruption. Backups of all images should be made at least weekly, ideally daily, on a rotation of four different hard drives, one per week. In addition to this, migration should be used to ensure that data remains readable. Every five years, data should be copied to new, up-to-date hardware (Ball 1998). Analogue storage is just as significant as digital storage in the preservation of digital images. It is important that photographs are printed on acid-free paper with archivally sound inks, from a printer that has been colour calibrated. Prints should have a minimum resolution of $300 \mathrm{dpi}$. Once printed, they should be stored in archival sleeves in order to protect the surface.

\subsection{Access to Documentation}

Access to documentation is not well-defined within existing best practice. A central archive is significant, such that conservation images are not separated from other images and documentation of objects (Stevenson 2006). If one central database is not possible, photographs should be linked or associated in some way with all other records concerning an object (Keene 1998). These connections are not only important to ease of access, but to ensuring that no information or documentation regarding an object, once created, is lost.

\subsection{Lifespan}

One important thing that current best practice literature does not address, but must be established, is the lifespan required of the documentation produced by conservators. The best way to 
understand how the conservation record will be used in the future is to first understand how current conservators use old photographs. In order to better understand current usage, follow-up interviews were conducted with conservators at two museums which have substantial photographic archives who responded to the questionnaire. The conservators both noted that at the moment, the benefit that would come of finding something useful in the archive is outweighed by the cost in terms of time it would take to find that resource, as the archives are all physical records. However, there is also a significant barrier in terms of time and economic cost to digitise all of the records and photography. That these conservators would use photos from 100 years ago, if access were easier and faster, allows us to extrapolate that conservators 100 years in the future will use photographs from the present day. Consider, however, that 100 years encompasses almost the entire history of photography. It is therefore possible that the acceptable lifespan should in fact be longer, something that may be observed as the length of the history of photography approaches and passes the span of utility of a photograph. 'Best practice', then, should indicate a lengthier preservation goal, on the order of 500 years.

\section{SURVEYING CONSERVATORS}

The questionnaire was used to determine how conservators document their work in practice, and to understand how these practices differ from the 'best practice' suggested by various guidelines. This will serve to illuminate what aspects of 'best practice' are, in fact, impractical for conservators, and potentially why these practices are troublesome.

All of the conservators surveyed indicated that they were producing digital photographs as opposed to still using film photography, and 25 out of 30 indicated that they photograph at least $75 \%$ of objects. This proves a previous hypothesis: digital photography has become the norm in conservation, creating an enormous archive of digital images across the field.

\subsection{Storage of Photographs}

Responding conservators were asked how and where photographs were stored, and whether or not analogue copies were kept as well as digital copies. Figure 1 compiles the responses to this question.

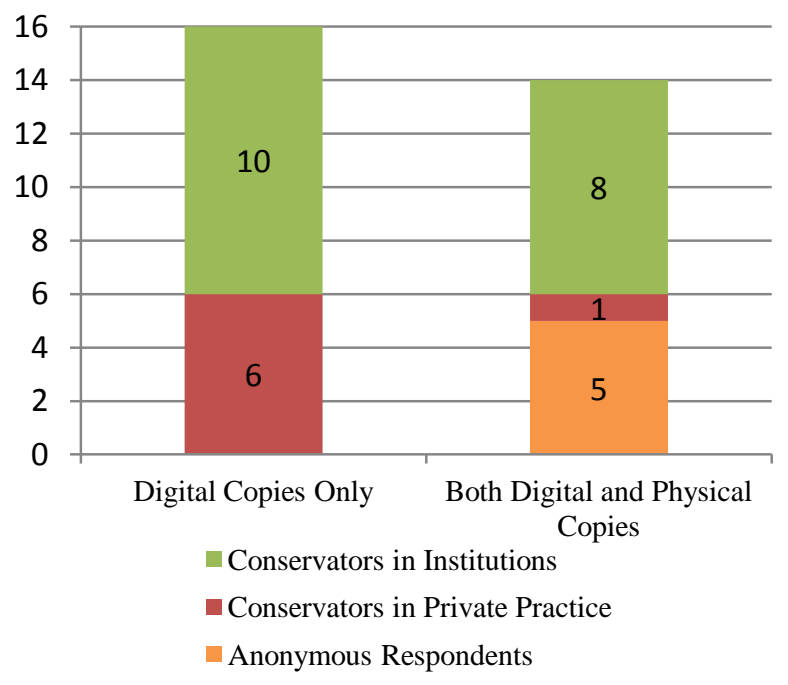

Figure 1. Breakdown of Storage Methods
For institutional conservators, the split between using only digital storage and keeping both physical and digital copies is almost even. However, some of the conservators who responded that they keep both physical and digital copies do not do so for every object that they treat. The selection process for these conservators is based on the scope of treatment or loan requirements. Records of minor treatments were noted by one conservator as being kept in digital format only, and two responses stated that records were only printed for loans. Conservators in private practice largely favoured storage of records in solely digital formats, although some indicated that they would print records on request.

\subsection{Maintenance of Storage}

Given that all of the responding conservators use digital storage in some manner for their records, the maintenance of this storage is extremely important. As such, respondents were asked if and how their digital storage systems are maintained. Figure 2 shows the different maintenance techniques undertaken in institutions and private practice. Note with this chart that some conservators use more than one technique; for example, each conservator who listed migration as a technique also employs refreshing in conjunction.

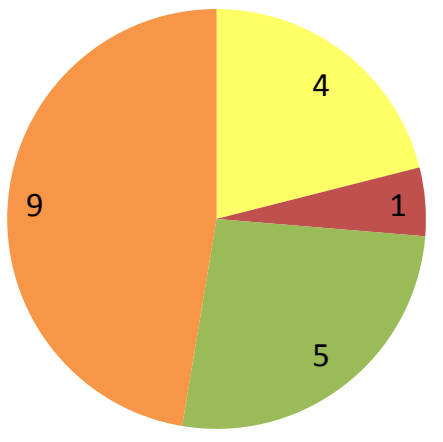

A. Conservators in Heritage Institutions

$\begin{array}{ll}\text { Refreshing } & \text { Migration } \\ \text { None/Unknown } & \text { Handled by IT Dept. }\end{array}$

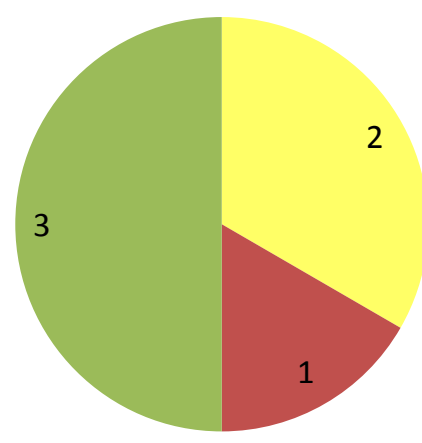

B. Conservators in Private Practice

Figure 2. Data maintenance practices of conservators in both private practice and within heritage institutions

Two private practice conservators responded that their form of maintenance for their digital storage is to store their photographs in two separate locations, on two separate hard drives. While this practice, known as doubling, is a safeguard against catastrophic loss, it is not really a form of maintenanceeach separate digital storage area is subject to deterioration and 
obsolescence, and simple doubling does not prevent either of these (MacLean 1998).

Another problematic response, given by six institutional conservators, is that they are unaware of what maintenance is undertaken because it is all handled by their IT department. Together, 14 of the 30 conservators surveyed either undertake no maintenance on their digital storage, or are unaware of what is done by others, if anything.

\subsection{Associated Information}

Another aspect of storage is the connection made between documentation and other information, such as catalogues or older records. Conservators were asked what curatorial or other information is kept or associated with photographs. Responses to this question were textual and very varied, and as such are not shown in a visual form here.

The most common response was that photographs are associated in some way with the treatment record for the object. The methods of doing so ranged from naming the photograph file in a way that treatment number is included to inserting images into textual reports. More than $65 \%$ of conservators surveyed directly associate their documentary photographs with the treatment record of the object. Some institutional conservators are able to do this very easily, and to include much more associated information, by putting photos into their institution's database. In most cases, this associates them not only with treatment records but with records from other departments, such as curatorial records. However, some conservators store photographs in their own folders, and label the images with accession number, object number, or other museum identification number. While this means that records are stored apart from each other, the numbering system means that locating information related to the object is not particularly difficult.

\subsection{Accessing Documentation}

Conservation records are not created solely for the use of the conservator; at the very least, they provide a record of treatment for future conservators, but also have the potential to be accessed by others in the heritage sector for a variety of reasons. The responding conservators were asked if other departments within their institution were given access, and if other institutions or outside persons were given access in any form. 7 of the 18 institutional conservators explained that they have an institution-wide database, which grants any member of staff access to these photographs. One conservator indicated that their institution has a database that is not only available to others within the museum, but is made available online to the general public. On the other end of the spectrum, 7 conservators said that photographs were rarely or never made accessible to anyone outside of conservation. Some of these same conservators also noted that they did not think other departments or institutions would be interested, but that they tend to grant access to photos if requested.

Conservators in private practice indicated that fewer people were granted access to their records. For the most part, it was explained that due to client confidentiality and copyright, records are either never shared, or only shared with the owner's permission when deemed justifiable. It was not explained what reasons for access constituted 'justifiable'. The records of private conservators are divided into two categories: those records which stay with the conservator and those which stay with the object when it is returned to its owner, both of which are significant.

\subsection{Issues Raised by Survey Responses}

If we assume that conservators are aware of best practice, but are not currently following best practice guidelines routinely or consistently, then one must assume that there are other factors preventing them from doing so.

The questionnaire results reveal that many conservators do not retain a physical copy; lack of time or economic resources could be the cause of this. The reasons for the general lack of proper maintenance of digital storage must also be considered in order to develop a methodology that is useful to conservators. If conservators do not know that data deteriorates, or that the lifespan of a hard drive is less than ten years, they will not be able to account for that and prevent it. There is also the potential that conservators do not see this as part of their job, as it is something handled by other departments in many institutions. Maintenance of digital storage also has resource costs, both economic and in terms of time spent. Economic costs come not only when the storage system is first created, in terms of buying the necessary hardware and software, but annual running costs as well. The amount of time spent on maintaining digital storage can also be costly; it is beneficial for data to be refreshed as often as daily, even without such frequent intervention the larger tasks of migration or emulation are particularly time-consuming. Smaller tasks such as colour calibration and formatting of files when moved from the camera to the computer can become very time-consuming as the quantity of data involved increases.

Overall, the costs of maintenance and preservation of digital storage can be high, and it is understandable that conservators must make changes to 'best practice' in order to make their processes practical and applicable.

\section{A NEW METHODOLOGY}

The questionnaire revealed that conservators do not always engage in the 'best practice' methods. It is for this reason that a consistent and practical methodology must be developed, one that is feasible for conservators. The goal remains the same; to ensure that conservation records, in particular digital records, are set up to be preserved for as long as possible. This method must be 'practical' in that the cost of engaging in various aspects, in terms of time, money, or other resources, cannot outweigh the benefit gained. The 'consistent' aspect of this new methodology is significant as well. It is important to have some degree of standardisation across conservation as a profession. If this is accomplished, the future of the conservation record will not only be secured, but it will be ensured that the record does not have gaps.

\subsection{Practical Documentation}

Some conservators noted in the questionnaire that they do not take before and after photos of very minor treatments, or those that do not enact any visible change on the object. This is acceptable under the 'best practical' method, as it not only saves time and effort, but in the long run reduces the storage space necessary. This is a form of objective selection, it should be noted; instead of later choosing that these photographs do not need to be preserved, it is decided from the outset that they 
are unnecessary. In addition to this, it is largely unnecessary for conservators to colour calibrate their digital cameras. Colour standardisation can be reached to an acceptable degree through the use of colour targets, which along with scales must be included in every photograph. Conservators are also still expected to take before, during, and after-treatment photographs for the majority of treatments.

\subsection{Modified Storage Methods}

The first thing to consider with storage is whether it is costeffective to use both digital and analogue storage. Consider that the lifespan being aimed for, as determined by the case studies, is 500 years; hard drives must be replaced every 5 years, which results in 100 migrations and thousands of daily or weekly backups, following the 'best practice' methodology. Even with a hypothetical $1 \%$ migration failure rate, the chain is broken and data is lost. Archivally sound paper, properly stored, can last for the full 500 years, making hard copies invaluable. Therefore even the 'best practical' method still involves both analogue and digital copies of documentation. Many conservators already acknowledge using this practice. Those who only use digital storage may need to invest in printers, ink, paper, and the like; however, the cost of this is clearly outweighed by the benefit of having a storage system that is stable on the same order of magnitude as the desired lifespan of documentation.

The first step in the storage of digital photographs is selection for survival. Conservators must actively choose which photographs they think best represent an object before and after treatment. There is the risk that future conservators will not find useful the same things that current conservators do; however, there is also the risk that attempting to preserve too much will result in none of it surviving. One to two photographs each for before, during, and after treatment, for a total of three to five photographs, should suffice for almost all objects. Fewer are necessary for simpler treatments.

Then there are specifics of digital storage that must be considered. A TIFF file with EXIF metadata remains the recommended file type. Although many conservators were unaware of what metadata is kept, metadata remains significant, and conservators should set their cameras to automatically capture and include EXIF data. The previous recommendations regarding resolution are still valid, requiring a minimum of 300 dpi. What is not required of conservators in the 'best practical' method is to keep multiple variations of their images for 'archive' and 'access', as this increases the amount of data storage needed. An 'access' copy should still be made is if the conservator intends to manipulate the photo in any way. The benefit of having the original version to return to if something goes wrong during manipulation or the copy is damaged outweighs the cost of doing so.

One of the major revelations of the questionnaire results is that not all guidelines will work for all conservators. Nowhere was this more evident than in the difference between storage maintenance practices of conservators in large institutions and conservators in private practice or at small institutions. It is acceptable for institutional conservators to rely on their IT department for the maintenance of their data, if that option is available. However, an effort should be made to understand what maintenance the IT department performs. Ensuring the longevity of the conservation record is their responsibility, and while delegation is fine, it must be overseen. It is recommended that conservators with the benefit of an institutional archive make their own backups of records once every six months, backing up on a rotation of two hard drives. In the case of institutional loss, the conservator's archives will be no more than six months out of date, a very small loss when considered on the order of 100 years' preservation. On the other hand, conservators in private practice and those at smaller institutions must be more individually responsible for their records. It is recommended that private practice conservators establish a schedule for backing up to multiple hard drives in rotation, as suggested is 'best practice' by the AIC. However, backups can be made monthly rather than more frequently, reducing some of the time cost. Conservators should set aside the funding to purchase new hard drives every five to seven years. These purchases allow the use of migration as a maintenance technique as well as refreshing, another layer of protection ensuring that their hardware does not become obsolete.

\begin{tabular}{|c|c|c|c|}
\hline & \multirow{2}{*}{$\begin{array}{c}\text { Best } \\
\text { Practice }\end{array}$} & \multicolumn{2}{|c|}{ New Methodology } \\
\hline & & $\begin{array}{l}\text { Institutional } \\
\text { Conservators }\end{array}$ & $\begin{array}{l}\text { Conservators } \\
\text { in Private } \\
\text { Practice }\end{array}$ \\
\hline \multirow[t]{3}{*}{$\begin{array}{c}\text { Digital } \\
\text { Storage } \\
\text { Practices }\end{array}$} & $\begin{array}{l}\text { TIFF file } \\
\text { format with } \\
\text { EXIF } \\
\text { metadata }\end{array}$ & \multicolumn{2}{|c|}{$\begin{array}{l}\text { TIFF file format with } \\
\text { automatically-captured EXIF } \\
\text { metadata }\end{array}$} \\
\hline & $\begin{array}{l}\text { 'Access' } \\
\text { and } \\
\text { 'archival' } \\
\text { versions of } \\
\text { every photo }\end{array}$ & \multicolumn{2}{|c|}{$\begin{array}{l}\text { 'Access' copy only needed } \\
\text { when manipulating images }\end{array}$} \\
\hline & $\begin{array}{l}\text { Apply } \\
\text { procedures } \\
\text { to all photos } \\
\text { taken }\end{array}$ & \multicolumn{2}{|c|}{$\begin{array}{c}\text { Select for survival 3-5 photos } \\
\text { per object, based on complexity } \\
\text { of treatment and change in } \\
\text { appearance }\end{array}$} \\
\hline \multirow[t]{3}{*}{$\begin{array}{c}\text { Data } \\
\text { Maintenance } \\
\text { Practices }\end{array}$} & $\begin{array}{l}\text { Daily or } \\
\text { weekly } \\
\text { backups }\end{array}$ & $\begin{array}{l}\text { Biannual } \\
\text { backups plus } \\
\text { understanding } \\
\text { of institutions } \\
\text { procedures }\end{array}$ & $\begin{array}{l}\text { Monthly } \\
\text { backups }\end{array}$ \\
\hline & $\begin{array}{l}4 \text { hard } \\
\text { drives in } \\
\text { rotation }\end{array}$ & \multicolumn{2}{|c|}{3 hard drives in rotation } \\
\hline & $\begin{array}{l}\text { Replace } \\
\text { HDD every } \\
5 \text { years }\end{array}$ & \multicolumn{2}{|c|}{ Replace HDD every 5-7 years } \\
\hline
\end{tabular}

Figure 3. Table showing the previous best practice

recommendations in comparison with the recommendations of the new methodology, for both institutional and private practice conservators.

\subsection{Practical Use \& Access}

In general, institutional systems have already put into place the 'best practical' method for accessing photographs. Many are available at least across departments. However, these decisions are mostly up to the institutions, not the individual conservators. What conservators can do is promote the sharing of knowledge and information. Conservators should also ensure that the file system and record labelling associate objects with their records. For both institutional and private practice conservators, the importance of a structured filing system and a readily understandable, consistently applied naming system cannot be stressed enough. This not only ensures that files are not accidentally 'lost' within the drive or network, but ensures that the images and records are easily accessible for the creating conservator, their colleagues, and future conservators. 
There are specific aspects to access that private practice conservators must consider. Their records are much more private than those of institutions, due to copyright and owner's wishes, and this is acceptable. What private conservators must ensure is that clients are provided with not only digital but hard copies of any documentation produced, such that the object treated is never separated from records about it.

\section{CONCLUSIONS}

Digital photography has provided conservators with the opportunity to quickly and easily document their work, and share that documentation with not only their fellow conservators, but other museum professionals and even sometimes with the public. Although it has proven to be an invaluable tool, it has been shown that there are many issues that come alongside digital media. Overall, this research has been successful in understanding how aware conservators are of these issues and how their practice reflects them. The questionnaire has provided insight into the practices of modern conservators, illuminating where they are successful in preserving their documentation and where there must be change.

These changes come in the form of a methodology that is more appropriate for the needs of the modern conservator. This includes variation of the recommended practices for conservators in private practice or small institutions versus those in large institutions. The time between backups is greater for conservators who have the benefit of an institutional archive, though the importance of personal responsibility in the maintenance of records is stressed. While this revised methodology lessens the burdens of 'best practice' on finances and time, it does not sacrifice the longevity of conservation documentation.

To answer a question posed at the very beginning of this paper, conservators have in fact begun to address the issues pertaining to digital media. Their practices are not perfect; there are aspects that could stand to be improved in order to ensure viability of digital resources. The future is not yet facing a 'blank' in the history of conservation. As long as conservators continue to improve and work at maintaining their documentation, future conservators may never again face a span of time from which information will be lost.

\section{ACKNOWLEDGEMENTS}

This paper is based on a dissertation submitted in partial fulfilment of the requirements for the degree of MA in Principles of Conservation at the Institute of Archaeology, University College London in 2012.

My utmost appreciation goes to the thirty conservators who responded to my questionnaire, and those who responded to follow-up questions. Without their cooperation and insight, this research would not have been possible. Sincere thanks are also due to my advisor, Dr John Merkel, Elizabeth Pye, James Hales, and Dean Sully for all of their assistance throughout this process.

\section{REFERENCES}

AIC, 1994. Code of Ethics \& Guidelines for Practice. American Institute for Conservation, Washington D.C.

Ball, S., Clark, S., and Winsor, P., 1998. The Care of Photographic Materials \& Related Media. Museums \& Galleries Commission, London.

Carlston, D., 1998. Storing Knowledge. In: B. Davis and M. MacLean (eds.), Time \& Bits: Managing Digital Continuity. The J. Paul Getty Trust, Los Angeles, pp. 21-31.

de Polo, A., and Minelli, S., 2006. Digital Access to a Photographic Collection. In: L. MacDonald (ed.), Digital Heritage: Applying Digital Imaging to Cultural Heritage. Elsevier, Amsterdam, pp. 93-114.

Deegan, M., and Tanner, S., 2006. Key Issues in Digital Preservation. In: M. Deegan and S. Tanner (eds.), Digital Preservation. Facet Publishing, London, pp. 1-31.

Greenstein, D., and Beagrie, N., 1998. A Strategic Framework for Creating and Preserving Digital Resources. Library Information Technology Centre, London.

Gschwind, R., Rosenthaler, L., Schnider, R., Frey, F., and Frey, J., 2005. Digital Image Picture Archives: Theory and Practice in Switzerland. In: J. Hemsley, V. Cappellini, and G. Stanke (eds.), Digital Applications for Cultural and Heritage Institutions. Ashgate Publishing, Hants, pp. 123-132.

Keene, S., 1998. Digital Collections: Museums and the Information Age. Butterworth-Heinemann, Oxford.

Lyman, P., and Besser, H., 1998. Defining the Problem of Our Vanishing Memory: Background, Current Status, Models for Resolution. In: B. Davis and M. MacLean (eds.), Time \& Bits: Managing Digital Continuity. The J. Paul Getty Trust, Los Angeles, pp. 11-20.

MacLean, M., 1998. Setting the Stage: Summary of Initial Discussions. In: B. Davis and M. MacLean (eds.), Time \& Bits: Managing Digital Continuity. The J. Paul Getty Trust, Los Angeles, pp. 32-35.

Pye, E., 2001. Caring for the Past: Issues in conservation for archaeology and museums. James \& James, London.

Scientific Working Group on Imaging Technology (SWGIT), 2010. Guidelines for the Forensic Imaging Practitioner. Retrieved 19 July 2012 from World Wide Web: https://www.swgit.org/documents/Current\%20Documents.

Stevenson, J., 2006. Digitisation Programmes in the V\&A. In: L. MacDonald (ed.), Digital Heritage: Applying Digital Imaging to Cultural Heritage. Elsevier, Amsterdam, pp. 69-92.

UPDIG Coalition, 2008. Universal Photographic Digital Imaging Guidelines, Universal Quick Guide v 4.0. Retrieved 19 July 2012 from World Wide Web: http://www.updig.org/.

Warda, J. (ed.), Frey, F., Heller, D., Kushel, D., Vitale, T., and Weaver, G., 2011. The AIC Guide to Digital Photography and Conservation Documentation. (Second Edition). AIC, Washington, D.C. 